\title{
ФУНКЦИОНАЛЬНОЕ ЗНАЧЕНИЕ ФОНДОВОГО РЫНКА ДЛЯ РАЗВИТИЯ ЭКОНОМИКИ РЕСПУБЛИКИ БЕЛАРУСЬ
}

\author{
(c) 2018 Ливенский Валентин Михайлович \\ кандидат географических наук, доцент кафедры финансов \\ Полесский государственный университет \\ 225710, Республика Беларусь, г. Пинск, ул. Днепровской флотилии, д. 23 \\ E-mail: livey@tut.by
}

В статье проведён качественный и количественный анализ деятельности фондового рынка Республики Беларусь; в рамках исследования выявлены проблемы его функционирования и предпринята попытка найти пути их решения.

Ключевые слова: национальная экономика, фондовый рынок, рынок акций, рынок облигаций.

В условиях современной мировой экономики во всех развитых и развивающихся государствах наличие развитого и функционирующего фондового рынка имеет для развития национальной экономики огромное значение. Фондовый рынок является составной частью финансового рынка и играет первостепенную роль в экономике страны, т.к. именно через фондовый рынок происходит перераспределение финансовых ресурсов между отраслями и сферами экономики, стимулирование инвестиций и их трансформация из непроизводительной в производительную форму, а также финансирование бюджетного дефицита. Основным преимуществом использования фондового рынка в качестве инструмента финансирования экономики является возможность принятия более взвешенных инвестиционных решений на основании рыночных цен с учётом реального положения всех участников рынка, тем самым повышая эффективность финансовой системы страны в целом [1]. В Республике Беларусь (РБ) в последнее время также большое внимание уделяется практической значимости развитию фондового рынка, что, в конечном счёте, предполагает выход национальной экономики РБ на совершенно новый уровень своего развития. В этой связи все заинтересованные лица на всех уровнях постоянно совершенствуют законодательство РБ по либерализации условий осуществления деятельности на фондовом рынке РБ, сближения законодательства и отчётности РБ с международными стандартами, создания условий для размещения ценных бумаг эмитентов из РБ на зарубежных фондовых площадках [2].

Здесь необходимо отметить, что на фондовом рынке РБ преобладающее значение имеют банки РБ, которые могут выступать как эмитентами, так и инвесторами или фондовыми посредниками. На рисунке 1 показана динамика объёмов торгов банками РБ на рынке акций за последние 4 года.

Как видим, активность банков РБ на рынке акций постоянно растёт. За 2017 г. объём торгов увеличился по сравнению с 2016 г. в 2,6 раз. Все операции были осуществлены посредством непрерывного двойного аукциона. Самыми активными банками были: ОАО «Белинвестбанк» (объём торгов - 391,15 млн. руб.), ОАО «АСБ Беларусбанк» (объём торгов - 50,66 млн. руб.), «Приорбанк» ОАО (объём торгов - 19,60 млн. руб.).

Так же отметим, что по состоянию на 01.01.2017 г. к обращению на бирже РБ допущены были акции 2358 предприятий юридических лиц. Из них акции 1 юридического лица (2 выпуска) - включены в котировальный лист «А» первого уровня, акции 18 юридических лиц включены в котировальный лист «А» второго уровня, акции 48 юридических лиц включены в котировальный лист «Б», в качестве внесписочных ценных бумаг к обращению допущены акции 2291 юридического лица. Эти данные отображены в табл. 1.

В разрезе видов ценных бумаг объём сделок с акциями в 2014 г. уменьшился на 15\%. При этом следует отметить существенное снижение размещения акций на первичном рынке. Данную тенденцию можно проследить на рисунке 2.

Суммарный объём вторичных торгов акциями за 2014 г. составил 479,2 млрд. руб. (уменьшение по сравнению с 2013 г. в 1,1 раза) или 37950012 акции (за 2013 г. объём составил 510,3 млрд. руб. или 141795577 акций). Количество 


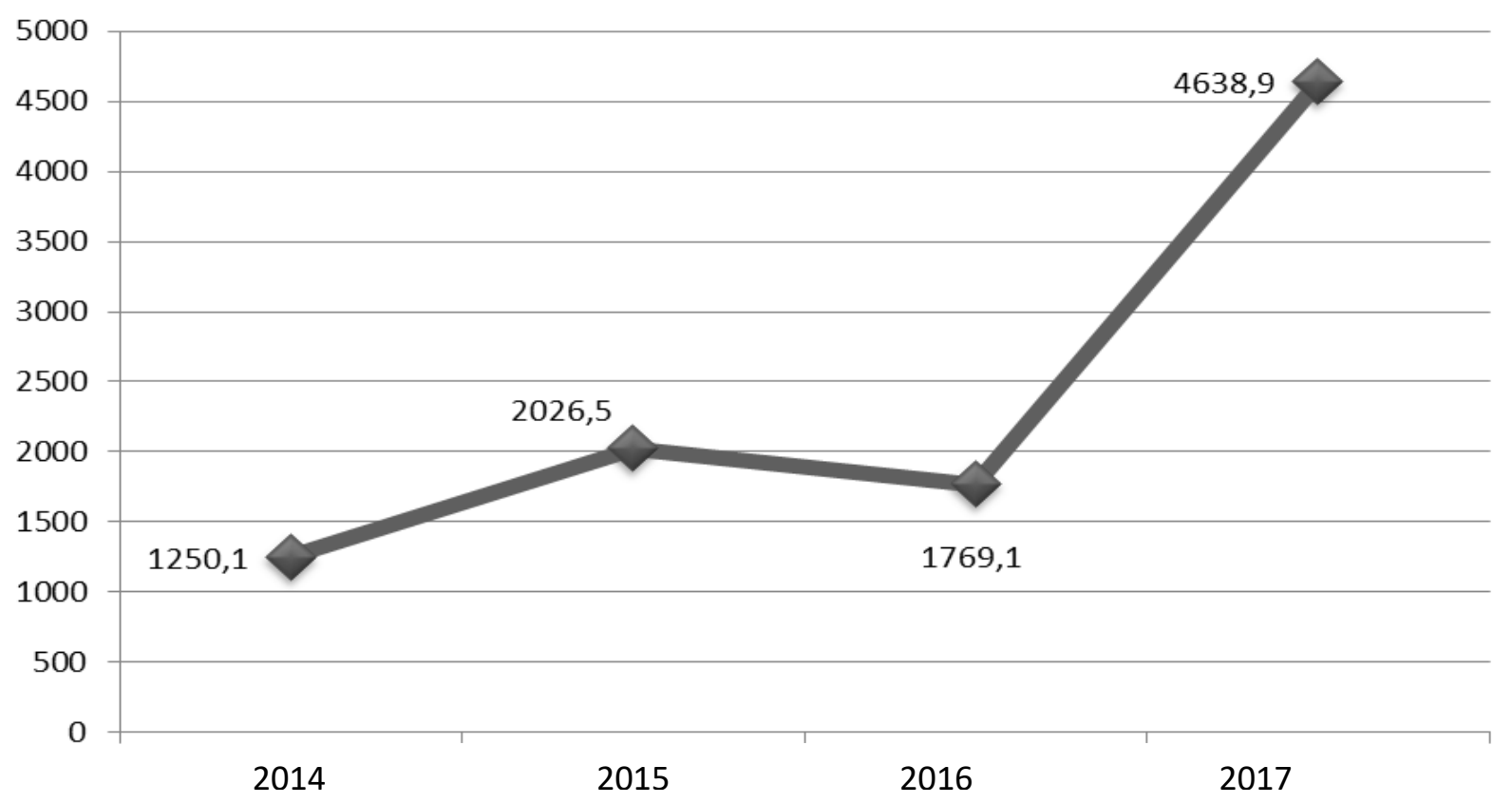

Puc. 1. Динамика объемов сделок банками РБ на рынке акций за 2014-2017 гг. Источник. Собственная разработка на основе [3]

Таблица 1. Котировальные списки по числу эмитентов РБ

\begin{tabular}{|c|c|c|c|c|c|}
\hline \multirow{2}{*}{ Вид ценой бумаги } & \multicolumn{3}{|c|}{ Котировальный лист } & \multirow{2}{*}{ Вне списка } & \multirow{2}{*}{ Всего } \\
\hline & Al & All & Б & & \\
\hline Акции & 1 & 18 & 48 & 2291 & 2358 \\
\hline Облигации субъектов хозяйствования & 9 & - & 5 & 52 & 66 \\
\hline Облигации местных займов & - & - & - & 17 & 17 \\
\hline
\end{tabular}

Источник [3]

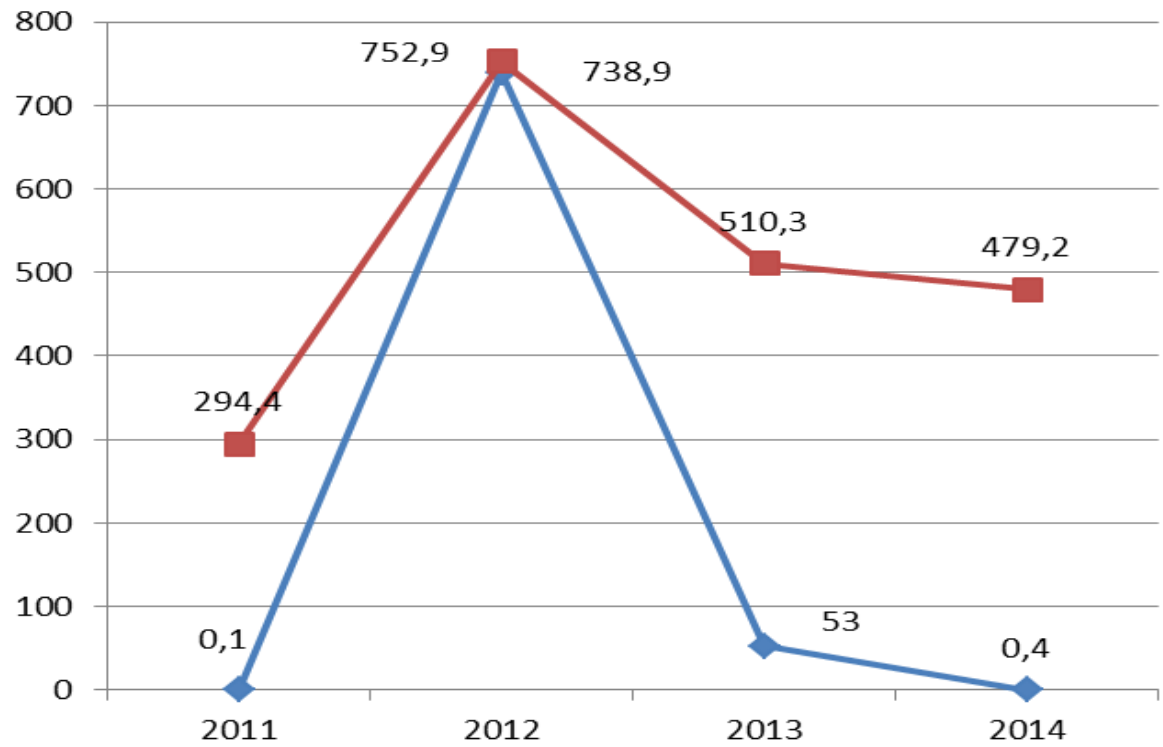

— Первычный рынок - - Вторичный рынок

Puc. 2. Динамика объемов сделок с акциями на первичном и вторичном рынках, млрд. pyб. (BYR) Источник. Собственная разработка на основе [3] 
сделок, заключённых с акциями в биржевой торговой системе в 2014 г., равно 5815 (за 2013 г. 6959 сделок). Количество эмитентов РБ, с акциями которых в отчётном периоде совершались сделки в общей сложности составило 263.

Бум роста объёма сделок с акциями связан с организацией и проведением IPO белорусских предприятий. В течение 2012 г. на биржевой площадке РБ было проведено публичное размещение акций следующих белорусских эмитентов: ОАО «Минский завод игристых вин», ОАО «Амкодор - Дзержинск», ОАО «Амкодор - управляющая холдинговая компания» и ОАО «Амкодор Унимод».

Что касается облигаций, то по состоянию на 01.01.2017 г. к обращению на секции «Фондовый рынок» были допущены облигации 66 эмитентов. Из них облигации 9 эмитентов - включены в котировальный лист «А» первого уровня, в котировальный лист «Б» включены 5 эмитентов, в качестве внесписочных ценных бумаг к обращению на бирже были допущены облигации 52 эмитентов.

За 2017 г. всего зарегистрировано было 456 выпусков корпоративных облигаций и облигаций местных займов, 211 эмитентов на сумму эмиссии 5572,31 млн. руб., в том числе:

- объём эмиссии облигаций банков РБ составил 3402,46 млн. руб. или $61,1 \%$ от общего объёма эмиссии;

Объём эмиссии зарегистрированных выпусков увеличился по сравнению с 2016 г. в 2,1 раза (за 2013 г. объём эмиссии составил 2675,01 млн. руб.), в том числе:

- облигаций банков - увеличение в 2,4 раза (за 2016 г. объём эмиссии и составил 1446,75 млн. руб.)

Информация о зарегистрированных в 2016 г. выпусках облигаций в разрезе эмитентов представлена в табл. 2.
Как видно из таблицы 2 , из 33 существующих банков РБ, 21 банк выпустил 120 выпусков облигаций в размере 3402,46 млн. руб. Данные выпуски составляют $61,1 \%$ от общего объёма эмиссии, что характеризует банки РБ как активных участников секции «Фондовый рынок».

В общем списке эмитентов РБ по состоянию на 01.01.2016 г. объём зарегистрированных и принятых к обращению облигаций банков РБ по сравнению с 01.01.2015 г. увеличился на 1,6\% и составил 5992,64 млн. руб.

Отметим, что Указом Президента РБ от 28 августа 2006 г. № 537 «О выпуске банками облигаций» банкам РБ представляется возможность выпускать свои облигации, обеспеченные всеми обязательствами по возврату основной суммы долга и уплате\% по предоставленным ими кредитам на строительство, реконструкцию или приобретение жилья под залог недвижимости. В 2014 г. объём эмиссии таких ипотечных облигаций составил 10,00 млн. руб. (BYN).

Общий объём эмиссии ипотечных облигаций, находящихся в обращении по состоянию на 01.01.2015 г. составил 14,68 млн. руб. (1 выпуск ипотечных облигаций ОАО «АСБ Беларусбанк» и 1 выпуск ипотечных облигаций ОАО «Белинвестбнк»).

Как видно, банки РБ очень тесно сотрудничает с Белорусской валютно-фондовой биржей, т.к. они являются основными её участниками.

Далее проанализируем, насколько на практике в РБ выполняются ключевые факторы (условия) для эффективной деятельности всех заинтересованных участников фондового рынка, а именно:

- свобода перемещения капитала;

- ликвидность ценных бумаг;

- инфраструктура фондового рынка РБ;

- финансовая культура и информационная прозрачность фондового рынка;

Таблица 2. Зарегистрированные выпуски облигаций в разрезе эмитентов за 2016 г.

\begin{tabular}{|l|c|c|c|c|c|c|}
\hline \multirow{2}{*}{\multicolumn{1}{|c|}{ Тип эмитента }} & \multicolumn{2}{|c|}{ Количество эмитентов } & Количество выпусков & \multicolumn{2}{|c|}{ Объем эмиссии } \\
\cline { 2 - 7 } & штук & $\begin{array}{c}\text { \% от общего } \\
\text { количества }\end{array}$ & штук & $\begin{array}{c}\text { \% от общего } \\
\text { количества }\end{array}$ & $\begin{array}{c}\text { Млн. руб. } \\
\text { (ВҮN) }\end{array}$ & $\begin{array}{c}\text { о от общего } \\
\text { объема } \\
\text { эмиссии }\end{array}$ \\
\hline Банки & 21 & 10,0 & 120 & 26,3 & 3402,46 & 61,1 \\
\hline $\begin{array}{l}\text { Небанковские организа- } \\
\text { ции }\end{array}$ & 154 & 73,0 & 272 & 59,6 & 1884,84 & 33,8 \\
\hline $\begin{array}{l}\text { Местные исполнительные } \\
\text { и распорядит. органы }\end{array}$ & 36 & 17,0 & 64 & 14,1 & 285,01 & 5,1 \\
\hline Итого: & 211 & 100 & 456 & 100 & 5572,31 & 100 \\
\hline
\end{tabular}

Источник. Собственная разработка на основе [3] 
- законодательная база;

- повышение финансовой грамотности и инвестиционной культуры населения на рынке ценных бумаг в РБ.

Свобода перемещения капитала в РБ. Следует отметить, что в настоящее время существуют некоторые препятствия по обращению акций и облигаций на фондовом рынке в РБ. Это, прежде всего, связано с нахождением значительной доли акций ведущих предприятий РБ в государственной собственности. Так, например, на 01.01.2018 г. государству принадлежало 83,6\% акций акционерных обществ РБ, что составляет 75,5\% от общего объёма их эмиссии. И пока государство крайне не заинтересовано в продаже частным инвесторам акций высокорентабельных белорусских предприятий. Более того, до сих пор существует список стратегических белорусских предприятий, акции которых продавать запрещено законодательно. Из этого следует, что широкое обращение акций на фондовом рынке РБ сведено к минимуму. Таким образом, при существующем достаточно жёстком контроле со стороны государства над фондовым рынком РБ о приемлемой свободе перемещения капитала говорить пока не приходиться [4].

Что касается физических лиц, то единственная возможность стать акционером появляется у них лишь тогда, когда они становятся работниками какого-нибудь белорусского предприятия, планирующего эмиссию акций, купив при этом небольшой «пакет» акций в надежде получать дивиденды. Это практика, которую прошли акционеры многих государственных белорусских предприятий. Акции успешных предприятий приобрести практически невозможно. Поэтому, единственным и возможным на сегодня видом ценных бумаг, по которым физические лица РБ могут заработать, является облигации. Однако данные облигации являются банковскими и приобретаются они на внебиржевом рынке.

К проблемам развития рынка акций можно отнести и ряд других факторов, например: недостаточная приватизация многих государственных белорусских предприятий, а это не позволяет использовать возможный потенциал рынка акций РБ для трансформации сбережений граждан республики в инвестиции, а также служит препятствием для привлечения в экономику РБ иностранных инвестиций; также низкий уровень прозрачности рынка акций, т.е. незаинтересованности белорусских эмитентов в раскрытии информации о результатах своей финансово-хозяйственной деятельности в соответствии с международными стандартами.

Ликвидность ценных бумаг в РБ. Отметим, что и уровень ликвидности рынка корпоративных ценных бумаг в РБ остаётся низким, что связано с небольшим объёмом предложенных для обращения на фондовый рынок ценных бумаг (главным образом акций). Так, например, в общем объёме сделок на вторичном рынке и в разрезе всех ценных бумаг доля акций составляет $1,9 \%$.

В связи с отсутствием котировок осуществлять спекуляции на фондовом рынке РБ, как это принято делать за рубежом, по-прежнему невозможно. Но покупать акции можно либо у физических лиц, ставших акционерами в процессе приватизации, либо при размещении новых эмиссий акций уже существующими ОАО. Но делать это, как правило, имеет смысл тогда, когда инвестор заинтересован не столько в получении дохода от самих акций, сколько в участии в управлении обществом. Надежды на широкое распространение практики размещения акций белорусских ОАО посредством IPO на белорусском рынке пока не оправдались.

Такая же низкая ликвидность и у корпоративных облигаций. Зачастую корпоративные облигации используются как замена банковскому кредиту, когда по каким-либо причинам банк не хочет выдавать предприятию кредит, но готов организовать выпуск облигаций и полностью выкупить их. Такие ценные бумаги до погашения находятся у банка, и ни на какой рынок не попадают, и соответственно их ликвидность не растёт. Такая стратегия во многом оправдана: в РБ пока мало представлены институты, которые традиционно вкладывают деньги в корпоративные облигации.

Существенная часть облигаций субъектов хозяйствования РБ номинирована в иностранной валюте, что обусловлено высокой волатильностью, а также значительной разницей процентных ставок по валютным и рублевым инструментам на финансовом рынке РБ. Отмеченная тенденция ведёт к росту валютных рисков как эмитентов, так и инвесторов, что может негативно отразиться на их финансовом состоянии.

Инфраструктура фондового рынка РБ. В настоящее время вся действующая инфраструктура фондового рынка РБ состоит из: ОАО «Белорусская валютно-фондовая биржа» (торговая 
система), централизованной двухуровневой депозитарной системы РБ и профессиональных участников рынка.

Из этого следует, что проведение всех сделок с акциями белорусских эмитентов возможно исключительно через торговую систему Белорусской валютно-фондовой биржи с привлечением профессиональных участников (далее - профучастники) - членов соответствующей фондовой секции. В тоже время, сделки купли-продажи с акциями белорусских эмитентов между профучастниками фондового рынка в РБ, осуществляемые через Белорусскую валютно-фондовую биржу, иногда связаны с дополнительными издержками, которые для миноритарных акционеров зачастую превышают выгоду от проведения сделки купли-продажи.

В тоже время, в соответствии с п. 65 Инструкции о некоторых вопросах вы-пуска и регистрации ценных бумаг в РБ, утверждённой постановлением Министерства финансов РБ от 11 декабря 2009 года № 146, решение о выпуске облигаций разрабатывается с широким участием профессиональных участников фондового рынка РБ [5]. И если размещение осуществляется на Белорусской валютно-фондовой бирже, то продажа облигаций может осуществляться только профессиональными участниками.

Финансовая культура и информационная прозрачность фондового рынка РБ. Здесь нужно отметить, что на сегодня на рынке ценных бумаг ещё нередко имеет место недобросовестная практика, связанная с манипулированием фондовым рынком РБ, в т.ч. неисполнением некоторых своих обязательств. Кроме этого, некоторые физические и юридические лица привлекаются иногда к административной ответственности за нарушения на рынке ценных бумаг, за нарушения порядка учёта сделок с ценными бумагами, а также незаконное разглашение информации о результатах финансово-хозяйственной деятельности белорусских эмитентов.

Для повышения прозрачности рынка ценных бумаг в РБ, согласно Закону «О рынке ценных бумаг» и в целях организации информационного обеспечения всех участников рынка ценных бумаг и государственных органов установлена обязанность регулятора рынка обеспечивать всех профучастников единым информационным ресурсом о рынке ценных бумаг в РБ.
Законодательная база фондового рынка РБ. Главным нормативным документом, регулирующим развитие фондового рынка РБ на долгосрочную перспективу, в настоящее время является «Программа развития рынка ценных бумаг РБ на 2015-2019 гг.». В данной программе широко предусмотрены основные мероприятия, ориентированные на создание необходимых предпосылок и условий привлечения инвестиций в экономику РБ посредством эмиссии акций и облигаций белорусских эмитентов. Ко всему прочему, среди принятых мер присутствуют мероприятия по совершенствованию системы государственного регулирования рынка ценных бумаг в РБ, развитие и совершенствование биржевой и депозитарной систем, налогового законодательства в части налогообложения доходов от операций с ценными бумагами и т.д.

Повышение финансовой грамотности и инвестиционной культуры населения В РБ. Сегодня Департамент по ценным бумагам на Интернет-странице Министерства Финансов РБ обеспечил широкое информационное поле для граждан, где подробно сказано о состоянии, правовых основах, тенденциях и перспективах долгосрочного развития фондового рынка РБ. Руководство и сотрудники Департамента так же часто организуют тематические семинары по конкретным вопросам, относящимся к компетенции Департамента, а также размещают публикации соответствующего законодательства о ценных бумагах РБ в периодической печати (журнал «Юрист»).

Отметим также, что мировой опыт свидетельствует о том, что срочный рынок занимает большую долю любой национальной экономики, и его ёмкость всегда прямо пропорциональна соответствующему уровню развития рыночных отношений в рамках экономики любого государства, её устойчивости. В развитых странах объём срочного рынка превосходит размер ВВП. В странах с развивающимися финансовыми рынками, в число которых можно отнести и РБ, срочные биржи и секции срочной торговли на биржах могут являться важнейшим стабилизатором как для национального финансового рынка, так и для национальной экономики в целом.

Система биржевого срочного валютного рынка РБ сходна с российской системой и строилась на основе опыта и учёта ошибок последней. Среди основных различий можно выделить следующие: 
- российский рынок работает на протяже- лись. нии последнего десятилетия, в РБ его пока нет;

- в России существует проблема регулирования срочного рынка: кто и за что отвечает в органах государственного управления, в РБ все вопросы регулирования определены в Правилах организации срочных сделок;

- Россия учится на своём опыте, а Беларусь на опыте России.

Фьючерсный рынок в РБ представлен только фьючерсными контрактами на доллары США, ЕВРО и российские рубли. В основе популярности таких операций с валютными фьючерсами лежат серьёзные колебания на мировых валютных площадках, что позволяет их участникам получать приличные доходы на курсовых разницах. На этом список ценных бумаг, допущенных и обращающихся на белорусском рынке ценных бумаг, заканчивается. А такие ценные бумаги, как векселя, опционы и др. на биржевом рынке с 1 квартала 2015 г. в обороте вообще не значи-

Таким образом, можно сформулировать следующие проблемы функционирования рынка ценных бумаг в РБ:

- жёсткий контроль со сторон государства не позволяет достаточно свободно перемещаться капиталу;

- тяжёлый доступ физических лиц к инструментам рынка ценных бумаг;

- низкий уровень объёмов торгов на вторичном рынке акций;

- низкая ликвидность корпоративных облигаций;

- сложный выход небольших компаний на рынок ценных бумаг;

- дублирование законодательства;

- неразвитость срочного рынка.

И как нам представляется, определив круг проблем развития рынка ценных бумаг в РБ, в дальнейшем профессионалы должны начать поиск основных направлений для их решения.

\section{Библиографический список}

1. Белоглазова Г. Н., Киевич А.В. Модернизация регулирования финансовых систем: поиск новых моделей // Банковское дело. 2011. № 7. С. 14-20.

2. Киевич А. В., Бухтик М.И., Койпаш Д. А. Роль доходов населения в финансировании реальных инвестиций в Республике Беларусь // Экономические науки. 2017. № 148. С. 83-88.

3. Отчёт о деятельности в 2017 году ОАО «Белорусская валютно-фондовая биржа» [Электронный ресурс].- Режим доступа: http://www.bcse.by/ru/about/index/49. - Дата доступа: 03.05.2018 г.

4. Киевич Д. А., Койпаш И.Ю. Инвестиционная деятельность в Республике Беларусь: проблемы и пути её совершенствования // Современные аспекты экономики.- 2017 . № 5 (237). С. 5-8.

5. Инструкции о некоторых вопросах выпуска и регистрации ценных бумаг: утв. Министерством Финансов 11.12.2009 г. № 146 (с изм. и доп. по состоянию на 30.06.2012 г.) // Консультант Плюс: Беларусь [Электронный ресурс].- Дата доступа: 19.05.2018 г. 